\title{
Appeal to Bystander Interventions: A Normative Approach to Health and Risk Messaging
}

Shawn Meghan Burn

Subject: Communication and Social Change, Health and Risk Communication, Communication and Culture

\section{Summary and Keywords}

Bystander intervention is a form of helping that occurs when onlookers intercede to provide direct or indirect aid to a victim. When bystanders step in to prevent or reduce harm to others, they act as agents of primary and secondary health prevention. But theory and research suggest the bystander intervention process is complex and multiple social-psychological and situational barriers imperil bystander action. Bystanders are often ill-prepared to intervene when others are at risk for emotional or physical harm. They may not notice that someone needs help due to distraction from self-focus, engagement in social interaction, intoxication, or aspects of the situation like crowding or noise. Due to inadequate knowledge, bystanders may misdiagnose the situation and believe intervention is unnecessary. The negative consequences of nonintervention may be unknown to them such that the situation fails to increase their empathic arousal and motivate their action. Lacking knowledge, they may not recognize the seriousness of the situation and or the potential costs of inaction, and so are insufficiently alarmed. Pluralistic ignorance can arise when multiple uncertain bystanders conceal their concern and hesitate to act, assuming others' inaction means intervention is inappropriate or unnecessary. When there are multiple witnesses, bystanders may assume their help is unneeded, place intervention responsibility on others, or feel less responsible for helping due to diffusion of responsibility. When the victim is not a member of their in-group, or is assumed at fault for their predicament, they may feel less empathy and a reduced responsibility to help. Or, bystanders may assign responsibility for intervention to the victim's friends or fellow in-group members, or to those "in charge" of the setting. Even when bystanders realize help is needed and take responsibility for helping, they may not act if they do not know how or lack confidence in their ability to successfully carry out the actions required to help. When they have the skills, they may not help if they perceive the costs of action to outweigh the benefits of action. Audience inhibition arising from group norms supporting inaction and from bystander worry about what others will think about 
them if they act unnecessarily or ineptly can prevent bystander action by increasing bystanders' perceived helping costs.

Recognition of bystanders as a potentially valuable public health asset has increased interest in promoting bystander intervention. Bystander intervention promotion and communications empower bystander action by combating intervention- and audiencespecific barriers to bystander intervention using targeted information, communications, and skills training. Theory and research suggest that effective promotions and communications foster context-specific attitudes, beliefs, norms, and skills such that bystanders: (1) are able to quickly and accurately identify a situation as interventionappropriate; (2) experience action-motivating arousal (including empathy) in the face of the event; (3) have positive attitudes towards intervention and perceive the benefits of action as outweighing the perceived costs; (4) are empowered to act and feel confident in their ability to effectively intervene (bystander efficacy); and (5) are resistant to evaluation apprehension and norms contraindicating action. Effective bystander intervention promotion draws on social psychology and communications studies, and best practices for health promotion and prevention programs. The application of social marketing and formative and summative program evaluation methods enhance the potential of bystander intervention promotions and communications to empower bystander action.

Keywords: bystander intervention, bystander efficacy, situational model of bystander intervention, bystander intervention promotion, empathy-altruism model, pluralistic ignorance

\section{Bystander Intervention Basics}

Witnesses are sometimes present when people experience events like heart attacks, accidents, drug overdose, assaults, or bullying. Bystander intervention is a form of prosocial behavior that occurs when onlookers (bystanders) act to provide direct aid or protection to victims, defend victims, confront or distract aggressors, alert authorities, or call police or emergency medical professionals on behalf of others. Bystanders may intervene alone or in concert with others to prevent or mitigate harm to victims. Their actions are sometimes heroic and life-saving.

Although the potential of bystander intervention for harm prevention and reduction is great, bystanders sometimes fail to intervene. For example, in the United States approximately $75 \%$ of the time bystanders do not provide needed cardiopulmonary resuscitation (CPR) for out-of-hospital cardiac events (Sasson et al., 2013). Similarly, although peers are present in approximately $80 \%$ of bullying episodes, and peer intervention effectively reduces bullying, child and adolescent witnesses of peer bullying intervene less than $20 \%$ of the time (Espelage, Green, \& Polanin, 2012; Polanin, Espelage, \& Pigott, 2012). Bystander intervention can benefit the both personal and community 
health and interest in its promotion is growing. This article unifies theory and research to provide practical recommendations for the design of bystander intervention education, skill training, and communications, as well as directions for future research.

Bystander intervention education and communications must be carefully designed to overcome potential bystander apathy (bystander inaction) and one of its most common forms, the bystander effect. First documented in a series of social-psychological experiments conducted by Bibb Latané and John Darley (1968, 1970; Darley \& Latané, 1968), the bystander effect describes how as the number of bystanders increases, the odds of intervention generally decrease. Although common sense suggests the odds of bystander action should increase when more possible helpers are present, decades of laboratory and field research, as well as anecdotal evidence, indicate that the presence of multiple others often inhibits bystander intervention (Fischer et al., 2011; Latané \& Nida, 1981).

When we're unaware of the situational influences on bystander intervention, we may erroneously blame bystander apathy on the selfish, uncaring nature of the bystanders. While it is true that personality traits and personal values affect rescuing behavior and also a person's enduring tendencies to share, help, and care for others (Midlarsky, Fagin Jones, \& Corley, 2005; Penner, Fritzsche, Craiger, \& Freifeld, 1995), the bystander intervention process is heavily influenced by situational factors. Even normally helpful people with prosocial personality traits are prone to bystander apathy under specific and somewhat common situational circumstances. Identifying and understanding those circumstances as they apply to the target bystander audience is the beginning of effective bystander intervention communications and promotion.

Bibb Latané and John Darley's $(1969,1970)$ situational model of helping is the bedrock of bystander intervention theory and practice because it directs our attention to some key causes of bystander apathy. People fail to intervene not because of apathy or indifference, they explained, but because a series of hurdles must be overcome before action is taken. Bystanders must notice the event, identify it as one where intervention is needed, take responsibility for intervention, decide how to help, and finally, act to intervene. Barriers at any of these decision points may halt the bystander intervention process (Latané \& Darley, 1968, 1970; Latané \& Nida, 1981). However, the bystander intervention decision process is not necessarily linear. Bystanders may "cycle back and forth" in indecision as they decide whether intervention is needed and whether it is their responsibility (Latané \& Darley, 1970).

Social psychologist Kurt Lewin (1951, p. 169) once said, "There is nothing so practical as a good theory" and the situational model of bystander intervention is a good theory indeed, strongly supported by research and with many potential practical applications. When thoughtfully applied, it tells us how we might empower bystanders to act. It is a focus of this article. But there are other theories and models of helping relevant to bystander intervention promotion. These include the arousal-cost-reward model of helping, the empathy-altruism model, and Bandura's social-cognitive theory. The basic principles of persuasion and influence and health communications research are also pertinent. These 
and other theories and perspectives relevant to bystander intervention promotion are integrated throughout this essay. Although these differ from one another in some important ways, and some are not specifically focused on bystander intervention, aspects of each complement, reinforce, overlap with, and enhance the situational model. Together they point the way to the promotion of bystander intervention supportive norms, attitudes, beliefs, intentions, and behaviors.

\section{The Bystander Intervention Process}

According to the situational model of helping, the bystander's decision to intervene requires a series of decisions that begins with the bystander noticing the event. As Latané and Darley (1970, p. 31) put it, "The external event has to break into his thinking and intrude itself upon his conscious mind." When bystanders are otherwise occupied due to self-focus, sensory or social distractions, or responsibilities, a failure to notice barrier stalls the bystander intervention process. For example, at a bar, or party, bystanders might not notice a sexual assault perpetrator taking advantage of an intoxicated person because they are distracted by their own social activities and their attentional and perceptual processes are compromised by intoxication (Burn, 2009). In high-density settings, like crowded cities or schools, inattention to other people may be an adaptive learned response; otherwise, personal goal accomplishment is hindered due to recurring distraction (Milgram, 1970).

After noticing the situation, the second step is for bystanders to identify the situation as intervention-appropriate. After all, if a potential rescuer fails to recognize that another person needs assistance they are unlikely to intervene. A failure to identify the situation as intervention appropriate barrier occurs when ignorance or ambiguity prevents bystanders from correctly interpreting a situation as warranting intervention. For example, bystanders may underestimate the negative impacts on the targets of racist jokes or comments and therefore be unmotivated to intervene. Guests at a party may assume that sexual contact between two partygoers is consensual when it is not. The signs of a heart attack or stroke may be misinterpreted as someone simply "under the weather."

Violent and dangerous emergencies decrease bystander apathy and the bystander effect because they are less ambiguous and therefore more easily identified as intervention appropriate (Fischer et al., 2011). According to the arousal-cost-reward model of helping, bystanders are more likely to intervene when another's distress increases the bystander's arousal and the perceived rewards of intervention outweigh the costs of inaction, or alternatively, when the costs of inaction (such as guilt or shame) outweigh the costs of action (Fischer et al., 2011; Piliavin, Dovidio, Gaertner, \& Clark, 1981). Latané and Darley (1970) also suggested that the "reward-cost structure" of the situation affects the bystander's perceptions and actions. From the point of view of the arousal-cost-reward 
model, serious and dangerous emergencies foster the correct identification of a dangerous situation by increasing bystander arousal and the perceived costs of nonintervention (Fischer, Greitemeyer, Pollozek, \& Frey, 2006).

Empathy models of helping, like Batson's empathy-altruism model (Batson et al., 1989), suggest that unambiguous emergencies and profound victim distress are more likely to trigger an empathic emotional reaction from bystanders that motivates intervention. Empathy for the victim can lead to helping even when rewards are low and costs are high (Graziano, Habashi, Sheese, \& Tobin, 2007). Among early adolescent samples, for example, greater empathy for victims of bullying is associated with bystander intervention (Espelage, Green, \& Polanin, 2012).

Unfortunately, ambiguity in potential helping situations is relatively common and this inhibits bystander action when bystanders fail to identify the situation as intervention appropriate. For example, it may be unclear to the bystander whether a person has alcohol poisoning or is merely "sleeping it off," whether observed sexual contact between others is consensual, whether a person is having a heart attack, or when a situation is playful teasing or bullying. This bystander diagnostic challenge is often aggravated by pluralistic ignorance. When people are unsure, they typically turn to others to help them identity social norms and interpret ambiguous situations. The problem is that in a potential helping situation, uncertain bystanders appear calm and cool because they do not want others to perceive them as possibly overreacting. This gives rise to pluralistic ignorance when uncertain, inactive bystanders look to other uncertain, inactive bystanders and consequently all fail to identify the situation as intervention-appropriate (Latané \& Darley, 1968). In essence, bystanders adopt what they (mistakenly) think is the consensual definition of the situation as intervention-inappropriate and therefore fail to act (Prentice \& Miller, 1993).

If the bystander identifies the situation as intervention-appropriate, the third step is to assume responsibility for intervention. At this point, a failure to take responsibility barrier may occur. Bystanders may decline intervention responsibility for several reasons, including diffusion of responsibility. As the number of bystanders increases, responsibility becomes "diffused" such that each bystander feels a decreased obligation to respond (Latané \& Darley, 1970). Metaphorically speaking, diffusion of responsibility concept suggests the bystander effect occurs because responsibility for intervention is shared with other bystanders so the more bystanders present, the smaller an individual bystander's piece of the "responsibility pie." And, when many are believed to have witnessed an event, bystanders are also more likely to assume that someone else has already taken action. Diffusion of responsibility also reduces the psychological costs associated with nonintervention since those costs are shared with others (Latané \& Nida, 1981).

Bystanders may also accept or decline intervention responsibility depending on their relationship with the victim (Latané \& Darley, 1970). For example, research finds that bystanders feel more responsible for intervening when they have a relationship with the 
potential victim or the victim is an in-group member (Levine, Cassidy, Brazier, \& Reicher, 2002; Levine, Prosser, Evans, \& Reicher, 2005). Perceptions of similarity between oneself and others makes it easier to see things from the victim's perspective increasing feelings of empathy, which in turn increases the likelihood of intervention (Batson, Eklund, Chermok, Hoyt, \& Ortiz, 2007). The arousal-cost-reward model of helping suggests that the identification of the victim as a member of the bystander's in-group increases arousal and feelings of responsibility thereby increasing the costs of nonintervention (Dovidio, Piliavin, Gaertner, Schroeder, \& Clark, 1991). According to social identity theory, a shared group identity affects feelings of bystander responsibility and leads bystanders to act in ways that support the needs and goals of in-group members (Turner, 1985). However, when an in-group member is the aggressor, bystanders may look the other way unless they believe the aggressive member will damage the reputation of the group (Levine et al., 2002).

Latané and Darley (1970) also hypothesized that the degree of personal responsibility taken by bystanders is affected by their judgments of the victim, in particular, whether the victim "deserves" help. Bystanders are more willing to take responsibility for intervention when they believe the victim needs help through no fault of their own and is undeserving of their fate. If however, they believe the victim made personal choices that led to their need for help, they have less empathy for the victim and are less likely to assume responsibility for helping them (Weiner, 1995). For example, bystanders are less likely to intervene in cases of sexual assault if they believe victim was intoxicated or acted or dressed provocatively (Burn, 2009; Whatley, 2005).

Once bystanders notice the situation, identify it as intervention-appropriate, and assume intervention responsibility, the fourth step in the situation model is to decide how to help. In other words, bystanders need not only the will to intervene, but also the skills to intervene (Pöyhönen, Juvonen, \& Salmivalli, 2012). But when bystanders lack the situationspecific intervention skills, a failure to intervene due to a skills deficit may occur (Cramer, McMaster, Bartell, \& Dragna, 1988; Shotland \& Heinhold, 1985). For example, a large Japanese study found the most common reason participants gave for not performing CPR was lack of confidence in their ability to do it properly (Shibata, Tamiguchi, Yoshida, \& Yamamoto, 2000). Likewise, youth that feel capable of standing up for a bullied peer are more likely to intervene (Pöyhönen \& Salmivalli, 2008; Pöyhönen, Juvonen, \& Salmivalli, 2012). A meta-analysis of bystander intervention research found the presence of highly competent bystanders reduces the bystander effect (Fischer et al., 2011).

Considered through the lens of social-cognitive theory, the fourth step (deciding how to help) of the situational model is about bystander efficacy. According to this theory a precondition for action is self-efficacy, a personal belief that one can produce desired effects through action (Bandura, 1997). In this case, bystander efficacy, or bystanders' confidence in their ability to successfully carry out needed interventions, is important to motivate bystander action. For example, self-perceptions of bystander efficacy in regards 
to interpersonal violence and bullying are positively associated with bystander intervention behavior (Banyard, 2008; Pöyhönen et al., 2012).

The final, or fifth, step in the bystander intervention process is to act. At this step, bystander fears of embarrassment, awkwardness, or other social concerns may lead to a failure to intervene due to audience inhibition barrier. Latané and Darley (1970) noted that evaluation apprehension (anxiety at the thought of possible negative evaluations from others) contributes to audience inhibition and may preclude action (Latané \& Darley, 1970). For example, students' decision to defend victims of bullying depends in part on peer-group norms (Espelage, Green, \& Polanin, 2012). Children who overestimate peers' approval of bullying report lower levels of defending the victim and higher levels of joining in (Sandstrom, Makover, \& Bartini, 2013). The appraisal-inhibition model of prosocial behavior (van den Bos \& Lind, 2013) also suggests bystander apathy occurs because people think too much about what others will think when instead they should act on the basis of personal norms supporting intervention.

Audience inhibition sometimes results from situation- or group-specific norms contraindicating intervention (Brown \& Messman-Moore, 2010; Rutkowski, Gruder, \& Romer, 1983). When salient social norms are inconsistent with intervention, the social costs of action are greater and bystander intervention is reduced. For example, some men's groups have norms against interfering with another's sexual conquest (Burn, 2009; Carlson, 2008). When racist comments and jokes are normative in a group and are used to maintain group cohesion and relationships, bystanders may hesitate to speak out against them (Guerin, 2006). Norms of "anti-political correctness" may also prevent antiracist bystander action (Stewart, Pedersen, \& Paradies, 2014). Likewise, institutional norms may discourage bystander intervention when sexual harassers are members of high-status groups and harassment is normative in the organizational setting (Bowes-Speery \& O’Leary, 2005).

Both social cognitive theory and the arousal-cost-reward model suggest that expecting negative outcomes from action may pose barriers to action even when the situation is perceived as intervention-appropriate and diffusion of responsibility is not an issue. Anticipated negative outcomes may include material losses and social rejection or criticism and are often context-specific. For example, language proficiency and fear of authorities may prevent bystanders from calling police or medical professionals in cases of cardiac arrest (Sasson et al., 2013). In case of drug overdose, bystanders may be reluctant to call 911 because in their community, police also respond to 911 calls (Giglio, Guohua, \& DiMaggio, 2015). The research literature on bystander antiracism, which is about actions taken to speak out about or to involve others in responding against interpersonal or systemic racism, notes that perceived costs such as fear of losing friends, embarrassing others, and retaliation pose obstacles to intervention (Nelson, Dunn, \& Paradies, 2011). 


\section{Promoting Bystander Intervention With Informational and Persuasive Messages}

Bystander intervention promotions and communications include the targeting of intervention-relevant attitudes, knowledge, beliefs, and norms. They provide information to increase awareness, to reduce bystander uncertainty, and to counter misperceptions that stymie bystander action. They use the principles of persuasion to inspire bystanders to act. The art and science of bystander intervention promotion and communications is relatively new, but theory and research provide useful direction for further research and application.

From the situational model, it follows that one purpose of bystander education and messages is to increase bystanders' diagnostic abilities such that they notice the situation when it occurs, and quickly and correctly identify it as intervention-appropriate.

Bystanders need to know enough about the situation to prevent ambiguity and ignorance from prematurely terminating the bystander intervention process. In other words, the failure to identify the situation as intervention-appropriate barrier arises from ambiguity and uncertainty, so increasing clarity through education or mass media is the way to "treat" this barrier. For example, on its website and through public service announcements and campaigns, the American Heart Association educates the public about the warning signs of heart attacks and strokes. Many sexual assault prevention programs include educational components that teach potential interveners how to recognize sexual predators and situations high in sexual assault risk. Overdose prevention programs include education about the signs and symptoms of overdose.

Persuading bystanders that the intervention situation is high in danger also appears important for decreasing intervention-sapping ambiguity and increasing interventionmotivating arousal. Information from credible, trustworthy experts about the short- and long-term effects on victims may increase intervention likelihood by increasing empathy, the perception of danger, and the costs of nonintervention. Vivid yet believable anecdotes and filmed victim stories also may be used for these purposes and may be more memorable (and thus, have more sustained effects). However, the use of emotion, including fear, requires finesse. Too much fear, for example, can lead to defensive denial and reduce credibility (Liberman \& Chaiken, 1992).

According to the elaboration likelihood theory of persuasion, if audience members are largely unmotivated and unconcerned about the intervention problem, and/or are low in a need for cognition, more dramatic testimonial messages may be particularly effective (Haugtvedt \& Petty, 1992; Petty \& Cacioppo, 1986). However, audiences are often mixed in their motivations and central and peripheral processes often act together to create attitude change (Petty, Wegener, \& Fabrigar, 1997). For this reason, bystander intervention campaigns may benefit from a mix of credible fact-based and emotion-based messages that are finely tuned to the audience and that appeal to both motivated and unmotivated 
audience members. Pretesting of messages is important for insuring that messages work as intended with the target audience.

Messages that are personally relevant and related to core audience values are generally more effective because they increase motivation to pay attention to the arguments, which leads to longer-lasting attitude change (Cacioppo, Petty, \& Sidera, 1982; Petty \& Briñol, 2012). They may also motivate action by arousing cognitive dissonance (when intervention is aligned with valued aspects of the self or group, action creates consonance, while inaction creates dissonance). Providing information about the frequency of the event, and the likelihood that the event could affect them or someone they care for, may increase personal relevance. The appraisal-inhibition model of prosocial behavior suggests that increasing the salience of personal norms supportive of intervention may also override perceived social norms contributing to audience inhibition.

According to the arousal-cost-reward model, bystanders are more likely to act when they perceive intervention rewards to outweigh intervention costs. From this point of view, framing bystander intervention as an opportunity for personal development, emphasizing the rewards of helping such as good mood, good "karma," or social acceptance, and playing up the costs of inaction, such as guilt or shame, or harm to the reputation of one's group, may promote bystander action (Penner, Dovidio, Piliavin, \& Schroeder, 2005). However, health communications research suggests that effective framing may depend on the perceived costs of the recommended preventative action (Gallagher \& Updegraff, 2012; Rothman \& Salovey, 1997). In the case of personal health prevention behaviors (e.g., exercising, getting health screenings), when the costs/risks of the recommended behavior are low, gain-framed messages (ones that emphasize what is to be gained from adopting a preventative action) are more effective than loss-framed messages. Conversely, if carrying out the promoted health behavior requires risk, loss-framed messages are more effective. This may mean that the effective framing of bystander intervention messages may depend on the perceived risks of performing a particular bystander intervention behavior.

Another purpose of bystander education is to reduce bystander susceptibility to common intervention barriers by increasing awareness of the bystander intervention process (including the bystander effect, pluralistic ignorance, and the diffusion of responsibility). Although research is limited, Beaman et al. (1978) found that listening to a lecture on Latané and Darley's research increased later bystander intervention. To break the "spell" of pluralistic ignorance and diffusion of responsibility, potential bystanders should be encouraged to gently express, either verbally or nonverbally, their concern that intervention is called for. Bystanders are less likely to fall prey to pluralistic ignorance when they see others' expression of concern and communicate with one another (Darley, Teger, \& Lewis, 1973; Fischer et al., 2011).

Research on one-sided versus two-sided messages suggests that where there are perceived norms or beliefs that contraindicate intervention, it is advisable to acknowledge and refute them to increase credibility, to decrease counterargumentation, 
and to create attitudinal resistance to attack (Crowley \& Hoyer, 1994). For example, where there are widely held victim-blaming norms and stereotypes negatively affecting bystander intervention, these should be countered to reduce their power. Likewise, sources of audience inhibition, such as specific norms supporting inaction, should be identified and countered or corrected. For example, data and discussion are used in some bystander intervention programs to counter victim-blaming stereotypes and to challenge masculinity norms associated with sexual assault (Gidycz, Orchowski, \& Berkowitz, 2011).

Increasing the salience of important group norms consistent with intervention is also advisable. The social norms approach to bystander intervention is based on the idea that people are more likely to intervene when they believe other bystanders are concerned and support intervention (Berkowitz, 2010). It suggests that bystanders may underestimate other bystanders' support for intervention and overestimate peers' acceptance of norms consistent with bystander apathy. Interventions that correct these misperceptions and make salient pro-intervention norms are expected to increase bystander action. For example, providing statistics, such as the percentage of peers supportive of the action, using target audience members in media and marketing materials, and using high-status peer opinion leaders to deliver messages, may increase perceived social desirability, thus serving as normative support and reducing audience inhibition.

Bystander intervention can also be promoted as consistent with friendship or other important group norms or as consistent with important collectivist social identities. For example, taking action to prevent another's sexual assault can be presented as consistent with "sisterhood" or "brotherhood" norms in sororities and fraternities. Campaigns fostering inclusive identities may promote antiracist intervention across ethnic lines (Nelson, Dunn, \& Paradies, 2011). When intervention requires "calling out" or acting to stop an aggressive in-group member (as is sometimes the case with bullying, and sexual violence), bystanders may be persuaded to intervene by framing in-group aggressors' actions as running counter to group norms and harming the group's reputation. However, emphasizing the social acceptance of a behavior to compel action requires that they believe it will result in positive outcomes, that they identify with the reference group, and the behavior is consistent with their values (Lapinski \& Rimal, 2005). A social norms approach to bystander intervention also suggests that bystander intervention education may be more effective when delivered to cohesive peer groups when members can agree on group norms supportive of intervention and influence each other to change (Gidycz, Orchowski, \& Berkowitz, 2011). 


\section{Empowering Bystanders Through Skills Development}

Bystander intervention promotions and communications empower bystanders to effectively and safely act on behalf of others. The situational model, social-cognitive theory, the arousal-cost-reward model, and the theory of planned behavior (Ajzen, 1991), as well as research on persuasion, all point to the importance of bystander skill training to increase bystander efficacy. Skills training should reduce the failure to intervene due to a skills deficit barrier by building potential bystanders' confidence in their ability to successfully intervene (bystander efficacy). Increasing bystander efficacy may also reduce evaluation apprehension arising from bystanders' insecurity in their intervention skills, consequently reducing a source of the failure to intervene due to audience inhibition barrier.

Bystander skills training and bystander intervention skills appeals should focus on specific things bystanders can say or do to effectively intervene. Bystanders must believe that the recommended actions will be effective in resolving or managing an event and believe that they can effectively enact them. Intervention options are sometimes derived from research or medical practice, but consultation with the expected bystander audience is strongly recommended to insure proposed intervention behaviors are realistic, acceptable, and "doable." Otherwise, the information source loses credibility and negative, rather than positive, bystander intervention attitudes and intentions are the result.

Recommended intervention options should consider potential costs to the bystander, such as physical, social, or emotional safety costs, and be selected to reduce the perceived costs of intervening. Simplifying intervention steps or options with memorable acronyms or catchphrases may speed learning and retention and retrieval, important because the opportunity for bystander action may occur long after training. For instance, the Chicago Recovery Alliance, which created one the first U.S. overdose prevention programs (OPPs), teaches potential bystanders the acronym "SCARE ME": Stimulate; Call 911, Airway; Rescue breathing, Evaluate, Muscular injection of Naloxone; and Evaluate (Lankenau et al., 2013). "Boosters," may also be necessary to refresh training and promote durability of promotion impacts (Nation et al., 2003). For example, key training program messages may be boosted through prompts, PSAs, or other promotional materials.

Social-cognitive theory suggests that the main sources of self-efficacy are mastery experiences, role models, and social support. Training should increase knowledge about effective intervention strategies and options and provide the opportunity for bystanders to practice specific intervention skills. Developmental stage should inform training design such that trainings are matched to the social-cognitive skills of the intended audience (Bradshaw, 2015). Role play, vignettes of common high-risk scenarios, and hands-on skill training (such as that using CPR dummies), may be used to practice and master new 
intervention skills. For example, Banyard, Moynihan, and Plante (2007) used active learning exercises, including role play, to help potential bystanders develop the skills needed for sexual assault intervention. Potter, Stapleton, and Moynihan (2008) used posters with scenarios and specific behavioral suggestions to promote knowledge of bystander intervention behaviors in regards to several types of violence against women.

To maximize attention, learning, and modeling, trainers and other sources of skills information should be credible sources to the audience of potential bystanders and effective communicators of intervention-relevant information. For many audiences, welltrained peer trainers are the most credible and effective communicators and coaches. Peer educators and trainers communicate peer acceptance of intervention and potential bystanders may more easily accept and remember recommended interventions when they believe similar others support those interventions. Diffusion of new health behaviors is also greater when the behavior is clearly supported and modeled by peer opinion leaders (Kelly, 2004). Several sexual assault bystander intervention programs have successfully employed a peer opinion leader strategy (Banyard, Moynihan, \& Crossman, 2009; Coker et al., 2011). Strategies for identifying peer leaders can be found in Valente and Pumpuang (2007).

\section{Bystander Intervention Promotion Should Be Context-and Evaluation-Driven}

Theory and research on prosocial behavior and health promotion provide general direction to bystander intervention promotion. However, effective application requires a context-driven approach that carefully considers the audience and local setting as well as the larger community and political environments in which bystander promotion occurs. As noted by Banyard (2015), a social-ecological model of bystander intervention that takes into account factors within the individual, factors related to close relationships with family and peers, factors related to local settings including workplace, school, and community, and aspects of the wider society and culture is most likely to be effective.

Successful bystander intervention promotions and messages are keyed to the context. The particular audience, type of "emergency" event, and aspects of the intervention environment affect the relative influence of the different barriers and affect important persuasive variables such as source credibility, message content, and channel. The audience and the social-ecological context in which bystander intervention occurs may affect the ideal delivery points for promotion, the characteristics of effective trainers, as well as the likely acceptance and feasibility of a recommended behavior or promotion.

Techniques and strategies from social marketing are useful for context-driven bystander intervention promotion. Social marketing, the use of marketing to design and implement programs to promote socially desirable behavior change, calls for a careful consideration 
of audience and contextual factors before designing and implementing a health promotion program (Grier \& Bryant, 2005). In social marketing the needs and concerns of the target audience and its subgroups drive the marketing process. Research is conducted to determine how to motivate different audience segments to voluntarily adopt the desired behaviors and is used to pretest of program or campaign components (Andreasen, 2006). Social marketing promotions refer to communications about the product to the target audience such as persuasive communications, signage, public service announcements, events, displays, and trainings (Grier \& Bryant, 2005). To influence voluntary behavior change, social marketing emphasizes that promotions should increase the perceived benefits and reduce the perceived costs of the desired behavior, and consider the behavioral options that may compete with recommended changes (Lee \& Kotler, 2011). Although there are few published studies on social marketing and bystander intervention, several studies support the social marketing of bystander intervention in regards to sexual violence (Potter, 2012; Potter, Moynihan, \& Stapleton, 2011; Potter \& Stapleton, 2012).

Program evaluation, both formative and summative, is important to insure bystander intervention promotion is effective with the target audience(s) and fits the intervention context(s). The objective of program evaluation is to obtain valid, reliable, and credible data about program performance to demonstrate a program's value or improve a program (Newcomer, Hatry, \& Wholey, 2015).

Ideally, formative program evaluations are conducted during program development and implementation and provide direction on how to best achieve program goals and improve programs. In this case, a needs assessment (a type of formative program evaluation) conducted with interviews, surveys, or focus groups with segmented samples of the target audience is essential to explore the bystander intervention context and behavior from the perspective of different subgroups within population for whom the campaign is intended. For example, the bystander intervention barriers in the case of sexual assault differ for men and women; for this reason gender-specific education and campaigns are recommended (Gidycz et al., 2011; Burn, 2009). The practice of "targeted communication" developed with a certain segment of the population in mind is popular in health education and health communication and supported by research (Noar, Benac, \& Harris, 2007).

Based on needs assessment data, specific promotion goals are formulated and promotion content and outcome measures are developed. Once a promotion or program is designed to reflect specific needs, it should be pilot-tested and evaluated. Based on the results, program content or implementation is adjusted. Once the program or campaign is established, summative program evaluation is used to evaluate program success. Summative program evaluation provides evidence of program success and is often important to gain institutional or community support as well as staffing and funding.

Effective program evaluation requires outcome measures that accurately and reliably reflect and assess program outcomes that follow from specific program goals. Bystander intervention program evaluation outcomes may include community-level change such as 
reductions in morbidity or mortality, but more typical are outcome measures that focus on improvements in individuals' knowledge and awareness, intervention intentions, attitudes towards victims or intervention behaviors, and intervention skills. For instance, peerfocused overdose prevention programs train bystanders in the use of naloxone, a shortacting opioid receptor antagonist that counteracts respiratory depression from overdose. Program effectiveness is measured by the Brief Overdose Recognition and Response Assessment tool, which includes sixteen overdose scenarios (Green, Heimer, \& Grau, 2008; Jones, Roux, Stancliff, Matthews, \& Comer, 2014). 


\section{Discussion of the Literature}

Bystander intervention research begins in the late 1960s with Bibb Latané and John Darley's groundbreaking studies. Inspired by a 1964 incident where Catherine (Kitty) Genovese was murdered while as many thirty-eight witnesses failed to act, social psychologists Darley and Latané $(1969,1970)$ sought to explain why, despite the number of witnesses, action wasn't taken. They challenged common-sense explanations attributing the witnesses' inaction to a loss of compassion and empathy, alienation from society, or the effects of television violence. They contended that the unusual and unexpected nature of emergencies combined with the presence of other bystanders, made bystanders susceptible to social influences that thwart intervention. The bystander intervention process is complex, they explained, and barriers throughout the process inhibit helping.

Latané and Darley tested their hypotheses through a series of laboratory and field experiments. These studies included the "smoke-filled room" experiment (1968). Arriving for what they thought was a study on people's reactions to living in large metropolitan areas, male research participants were left to fill out preliminary paperwork. The researchers systematically manipulated whether a potential bystander was alone, with two passive experimental confederates, or with two other naive bystanders. Several minutes later, the researchers pumped smoke into the room. The results were clear: those in the room alone were significantly more likely to report the smoke (75\% within six minutes) than were those with two passive confederates $(10 \%)$ or with two other naïve research participants (35\%). Two years later (1970) they coined the term pluralistic ignorance to refer to ambiguous situations where bystanders are misled into inaction by the apparent lack of concern by others.

In the "seizure study," Darley and Latané (1968) tested their hypothesis that the presence of others may also reduce bystander intervention due to diffusion of responsibility. Women and men college student participants arrived to talk with other students about the personal problems faced by college students. To protect their privacy they would talk via an intercom system. The experimenter explained that although he wouldn't hear their discussion, he wanted each person to begin by presenting their problems to the group, after which all members could comment, followed by free discussion. All discussants, except for the research participant, were tape-recorded experimental confederates. The "victim" went first, talking of adjustment difficulties, and mentioning he was prone to seizures. When it was his turn to comment, he had a seizure. Stuttering and choking, he asked for help and said he might be dying; he choked, and then went silent. When participants believed the discussion was between them and one other person, $85 \%$ of participants sought help before the victim went quiet. When they thought they were with two other people, $62 \%$ intervened, and when they thought they were with five others, only $31 \%$ acted. 
Almost a decade after the original bystander intervention studies, Latané and Nida (1981) reviewed the research. Their analysis of 56 studies from 36 different research labs led them to conclude that the bystander effect had a "firm empirical foundation and has withstood the tests of time and replication" (p. 322). Fischer et al.'s (2011) quantitative meta-analysis of bystander intervention studies (which included 15 additional articles) also confirmed the robustness of the bystander effect, although later studies found smaller effects than earlier studies, and laboratory studies found larger effects than field studies.

Comparing the post-1981 research to prior research, Fischer et al. (2011) noted that more recent research shows that the bystander effect also occurs in the virtual world of the Internet, that it is stronger for less competent bystanders than for highly competent bystanders, and that dangerous emergencies reduce the bystander effect. In regards to this last finding, they suggested that in some dangerous situations, the presence of additional bystanders increases intervention likelihood by reducing the perceived costs of intervention. They suggested that this "positive bystander effect" occurs when bystanders believe that successful intervention requires the coordinated action of a group, or when they expect that others will offer needed social, physical, or psychological support for intervention. Others also remind us that groups can be sources of collective bystander action (rather than inaction) and that intervention depends not simply on the number of bystanders, but rather on the kinds of relationships between them (Rutkowski et al., 1983; Levine \& Crowther, 2008; Manning, Levine, \& Collins, 2007).

In their 1981 review, Latané and Nida lamented that social-psychological research on bystander intervention had not contributed to the development of practical strategies for increasing bystander action. Their concern was valid. Bystander intervention research was basic research rather than applied, mostly conducted by experimental social psychologists (who generally leave the practice application of basic research findings to others). The development of practical strategies would be up to problem-solvers who saw the relevance of bystander intervention to their problem of concern. Almost 25 years passed before these efforts began in earnest.

Research on bystander intervention promotion is limited but growing. To address specific problems, bystander intervention promotion researchers from multiple disciplines study the role of bystander intervention in primary and secondary prevention and problemspecific barriers to bystander intervention. They develop and test bystander intervention promotion "treatments" in both laboratory and field settings. To varying degrees, they use bystander intervention and health promotion theory to guide practice, but much of the work is somewhat atheoretical. Due to practical concerns, programs are often brief and limited in scope, and long-term impacts are rarely measured. Small to moderate effect sizes are typical. Nation et al. (2003) found that effective prevention programs were comprehensive, included varied teaching methods, provided enough exposure to have an effect ("sufficient dosage"), were theory-driven, tailored to the community and cultural 
norms of the participants, and made efforts to include the target group in program planning and implementation. These characteristics associated with effective prevention programs appear to apply to the success of bystander intervention programs.

Led by feminist, counseling, and community psychologists, the most extensive bystander intervention scholarship is in the area of sexual assault prevention (see Katz \& Moore, 2013, for a meta-analysis). Educational and school psychologists have created a literature on bystander intervention and K-12 bullying (see Polanin, Espelage, \& Pigott, 2012, for a meta-analysis). Other smaller bodies of research include bystander intervention in cardiopulmonary respiration and opioid overdose (from emergency medicine and public health researchers) and bystander anti-racism research (conducted primarily by social psychologists).

\section{Further Reading}

Banyard, V. L., Moynihan, M. M., Cares, A. C., \& Warner, R. (2014). How do we know if it works? Measuring outcomes in bystander-focused abuse prevention on campuses. Psychology of Violence, 4(1), 101-115.

Fischer, P., Krueger, J. I., Greitemeyer, T., Vogrincic, C., Kastenmüller, A., Frey, D., ... \& Kainbacher, M. (2011). The bystander-effect: A meta-analytic review on bystander intervention in dangerous and non-dangerous emergencies. Psychological Bulletin, 137(4), 517-537.

Gidycz, C. A., Orchowski, L. M., \& Berkowitz, A. D. (2011). Preventing sexual aggression among college men: An evaluation of a social norms and bystander intervention program. Violence Against Women, 17(1), 720-742.

Latané, B., \& Darley, J. M. (1970). The unresponsive bystander: Why doesn't he help? Englewood Cliffs, NJ: Prentice Hall.

Latané, B., \& Nida, S. (1981). Ten years of research on group size and helping. Psychological Bulletin, 89(2), 308-324.

Katz, J., \& Moore, J. (2013). Bystander education training for campus sexual assault prevention: An initial meta-analysis. Violence and Victims, 28(6), 1054-1067.

Noar, S. M. (2006). A 10-year retrospective of research in health mass media campaigns: Where do we go from here? Journal of Health Communication, 11(1), 21-42.

Piliavin, J. A., Dovidio, J. F., Gaertner, S. L., \& Clark, R. D., III. (1981). Emergency intervention. New York: Academic.

Polanin, J. R., Espelage, D. L., \& Pigott, T. D. (2012). A meta-analysis of school-based bullying prevention programs' effects on bystander intervention behavior. School Psychology Review, 41(1), 47-65. 


\section{References}

Ajzen, I. (1991). The theory of planned behavior. Organizational Behavior and Human Decision Processes, 50, 179-211.

Andreasen, A. R. (Ed.). (2006). Social marketing in the 21st century. Thousand Oaks, CA: SAGE.

Bandura, A. (1997). Self-efficacy: The exercise of control. New York: Freeman.

Banyard, V. L. (2008). Measurement and correlates of prosocial bystander behavior: The case of interpersonal violence. Violence and victims, 23(1), 83-97.

Banyard, V. L. (2015). Pieces of bystander action. In Toward the next generation of bystander prevention of sexual and relationship violence: Springer briefs in criminology (pp. 25-51). New York: Springer International Publishing.

Banyard, V. L., Moynihan, M. M., Cares, A. C., \& Warner, R. (2014). How do we know if it works? Measuring outcomes in bystander-focused abuse prevention on campuses. Psychology of Violence, 4(1), 101-115.

Banyard, V. L., Moynihan, M. M., \& Crossman, M. T. (2009). Reducing sexual violence on campus: The role of student leaders as empowered bystanders. Journal of College Student Development, 50(4), 446-457.

Banyard, V. L., Moynihan, M. M., \& Plante, E. G. (2007). Sexual violence prevention through bystander education: An experimental evaluation. Journal of Community Psychology, 35(4), 463-481.

Batson, C. D., Batson, J. G., Griffitt, C. A., Barrientos, S., Brandt, J. R., Sprengelmeyer, P., \& Bayly, M. J. (1989). Negative-state relief and the empathy: Altruism hypothesis. Journal of Personality and Social Psychology, 56(6), 922-933.

Batson, D. C., Eklund, J. K., Chermok, V. L., Hoyt, J. L., \& Ortiz, B. G. (2007). An additional antecedent of empathic concern: Valuing the welfare of the person in need. Journal of Personality and Social Psychology, 93(1), 65-74.

Beaman, A. L., Barnes, P. J., Klentz, B., \& Mcquirk, B. (1978). Increasing helping rates through information dissemination: Teaching pays. Personality and Social Psychology Bulletin, 4(3), 406-411.

Berkowitz, A. D. (2010). Fostering healthy norms to prevent violence and abuse: The social norms approach. In K. L. Kaufman (Ed.), The prevention of sexual violence: A practitioner's sourcebook (pp. 147-171). Holyoke, MA: NEARI Press.

Bowes-Sperry, L., \& O’Leary-Kelly, A. M. (2005). To act or not to act: The dilemma faced by sexual harassment observers. Academy of Management Review, 30(2), 288-306. 
Bradshaw, C. P. (2015). Translating research to practice in bullying prevention. American Psychologist, 70(4), 322-332.

Brown, A. L., \& Messman-Moore, T. L. (2010). Personal and perceived peer attitudes supporting sexual aggression as predictors of male college students' willingness to intervene against sexual aggression. Journal of Interpersonal Violence, 25(3), 503-517.

Burn, S. M. (2009). A situational model of sexual assault prevention through bystander intervention. Sex Roles, 60(11-12), 779-792.

Cacioppo, J. T., Petty, R. E., \& Sidera, J. A. (1982). The effects of a salient self-schema on the evaluation of proattitudinal editorials: Top-down versus bottom-up message processing. Journal of Experimental Social Psychology, 18(4), 324-338.

Carlson, M. (2008). I'd rather go along and be considered a man: Masculinity and bystander intervention. The Journal of Men's Studies, 16(1), 3-17.

Cialdini, R. B., Brown, S. L., Lewis, B. P., Luce, C., \& Neuberg, S. L. (1997).

Reinterpreting the empathy-altruism relationship: When one into one equals oneness. Journal of Personality and Social Psychology, 73(3), 481-494.

Coker, A. L., Cook-Craig, P. G., Williams, C. M., Fisher, B. S., Clear, E. R., Garcia, L. S., \& Hegge, L. M. (2011). Evaluation of Green Dot: An active bystander intervention to reduce sexual violence on college campuses. Violence Against Women, 17, 777-796.

Cramer, R. E., Mcmaster, M. R., Bartell, P. A., \& Dragna, M. (1988). Subject competence and minimization of the bystander effect. Journal of Applied Social Psychology, 18(13), 1133-1148.

Crowley, A. E., \& Hoyer, W. D. (1994). An integrative framework for understanding twosided persuasion. Journal of Consumer Research, 20(4), 561-574.

Darley, J. M., \& Latané, B. (1968). Bystander intervention in emergencies: Diffusion of responsibility. Journal of Personality and Social Psychology, 8, 377-383.

Darley, J. M., Teger, A. I., \& Lewis, L. D. (1973). Do groups always inhibit individuals' responses to potential emergencies? Journal of Personality and Social Psychology, 26(3), 395-399.

Dovidio, J. F., Piliavin, J. A., Gaertner, S., Schroeder, D. A., \& Clark, R. D., III. (1991). The arousal: cost-reward model and the process of intervention: A review of the evidence. Review of Personality and Social Psychology, 12, 86-118.

Espelage, D., Green, H., \& Polanin, J. (2012). Willingness to intervene in bullying episodes among middle school students: Individual and peer-group influences. The Journal of Early Adolescence, 32(6), 776-801. 
Fischer, P., Greitemeyer, T., Pollozek, F., \& Frey, D. (2006). The unresponsive bystander: Are bystanders more responsive in dangerous emergencies?European Journal of Social Psychology, 36, 267-278.

Fischer, P., Krueger, J. I., Greitemeyer, T., Vogrincic, C., Kastenmüller, A., Frey, D., ... \& Kainbacher, M. (2011). The bystander-effect: A meta-analytic review on bystander intervention in dangerous and non-dangerous emergencies. Psychological Bulletin, 137(4), 517-537.

Gallagher, K. M., \& Updegraff, J. A. (2012). Health message framing effects on attitudes, intentions, and behavior: A meta-analytic review. Annals of Behavioral medicine, 43(1), 101-116.

Gidycz, C. A., Orchowski, L. M., \& Berkowitz, A. D. (2011). Preventing sexual aggression among college men: An evaluation of a social norms and bystander intervention program. Violence Against Women, 17(6), 720-742.

Giglio, R., Li, G., \& DiMaggio, C. (2015). Effectiveness of bystander naloxone administration and overdose education programs: A meta-analysis. Injury Epidemiology, 2(1), 1-9.

Graziano, W. G., Habashi, M. M., Sheese, B. E., \& Tobin, R. M. (2007). Agreeableness, empathy, and helping: A person $\times$ situation perspective. Journal of Personality and Social Psychology, 93(4), 583-600.

Green, T. C., Heimer, R., \& Grau, L. E. (2008). Distinguishing signs of opioid overdose and indication for naloxone: An evaluation of six overdose training and naloxone distribution programs in the United States. Addiction, 103, 979-989.

Grier, S., \& Bryant, C. A. (2005). Social marketing in public health. Annual Review Public Health, 26, 319-339.

Guerin, B. (2006). Combating everyday racial discrimination without assuming "racists" or "racism": New intervention ideas from a contextual analysis. Behavior and Social Issues, 14(1), 46-70.

Haugtvedt, C. P., \& Petty, R. E. (1992). Personality and persuasion: Need for cognition moderates the persistence and resistance of attitude changes. Journal of Personality and Social Psychology, 63, 308-319.

Jones, J. D., Roux, P., Stancliff, S., Matthews, W., \& Comer, S. D. (2014). Brief overdose education can significantly increase accurate recognition of opioid overdose among heroin users. International Journal of Drug Policy, 25, 166-170.

Katz, J., \& Moore, J. (2013). Bystander education training for campus sexual assault prevention: An initial meta-analysis. Violence and victims, 28(6), 1054-1067. 
Kelly, J. A. (2004). Popular opinion leaders and HIV prevention peer education: Resolving discrepant findings, and implications for the development of effective community programmes. AIDS Care, 16(2), 139-150.

Lankenau, S. E., Wagner, K. D., Silva, K., Kecojevic, A., Iverson, E., McNeely, M., \& Kral, A. H. (2013). Injection drug users trained by overdose prevention programs: Responses to witnessed overdoses. Journal of Community Health, 38(1), 133-141.

Lapinski, M. K., \& Rimal, R. N. (2005). An explication of social norms. Communication Theory, 15(2), 127-147.

Latané, B., \& Darley, J. M. (1968). Group inhibition of bystander intervention in emergencies. Journal of Personality and Social Psychology, 10, 215-221.

Latané, B., \& Darley, J. M. (1969). Bystander “apathy.” American Scientist, 57(2), 244268.

Latané, B., \& Darley, J. M. (1970). The unresponsive bystander: Why doesn't he help? Englewood Cliffs, NJ: Prentice Hall.

Latané, B., \& Nida, S. (1981). Ten years of research on group size and helping. Psychological Bulletin, 89(2), 308-324.

Lee, N. R., \& Kotler, P. (2011). Social marketing: Influencing behaviors for good. Sage.

Levine, M., Cassidy, C., Brazier, G., \& Reicher, S. (2002). Self-categorization and bystander non-intervention: Two experimental studies. Journal of Applied Social Psychology, 32(7), 1452-1463.

Levine, M., \& Crowther, S. (2008). The responsive bystander: How social group membership and group size can encourage as well as inhibit bystander intervention. Journal of Personality and Social Psychology, 95(6), 1429-1439.

Levine, M., Prosser, A., Evans, D., \& Reicher, S. (2005). Identity and emergency intervention: How social group membership and inclusiveness of group boundaries shape helping behavior. Personality and Social Psychology Bulletin, 31(4), 443-453.

Lewin, K. (1951). Field theory in social science: Selected theoretical papers. New York: Harper \& Row.

Levine, M., \& Crowther, S. (2008). The responsive bystander: How social group membership and group size can encourage as well as inhibit bystander intervention. Journal of Personality and Social Psychology, 95(6), 1429-1439.

Liberman, A., \& Chaiken, S. (1992). Defensive processing of personally relevant health messages. Personality and Social Psychology Bulletin, 18(6), 669-679. 
Manning, R., Levine, M., \& Collins, A. (2007). The Kitty Genovese murder and the social psychology of helping: The parable of the 38 witnesses. American Psychologist, 62(6), 555-562.

Midlarsky, E., Fagin Jones, S., \& Corley, R. P. (2005). Personality correlates of heroic rescue during the Holocaust. Journal of Personality, 73(4), 907-934.

Milgram, S. (1970). The experience of living in cities. Science, 167(3924), 1461-1468.

Nation, M., Crusto, C., Wandersman, A., Kumpfer, K. L., Seybolt, D., Morrissey-Kane, E., \& Davino, K. (2003). What works in prevention: Principles of effective prevention programs. American Psychologist, 58(6-7), 449-456.

Nelson, J. K., Dunn, K. M., \& Paradies, Y. (2011). Bystander anti-racism: A review of the literature. Analyses of Social Issues and Public Policy, 11(1), 263-284.

Newcomer, K. E., Hatry, H. P., \& Wholey, J. S. (2015). Handbook of practical program evaluation. Hoboken, NJ: John Wiley \& Sons.

Noar, S. M., Benac, C. N., \& Harris, M. S. (2007). Does tailoring matter? Meta-analytic review of tailored print health behavior change interventions. Psychological Bulletin, 133(4), 673-693.

Penner, L. A., Dovidio, J. F., Piliavin, J. A., \& Schroeder, D. A. (2005). Prosocial behavior: Multilevel perspectives. Annual Review of Psychology, 56, 365-392.

Penner, L. A., \& Finkelstein, M. A. (1998). Dispositional and structural determinants of volunteerism. Journal of Personality and Social Psychology, 74(2), 525-537.

Penner, L. A., Fritzsche, B. A., Craiger, J. P., \& Freifeld, T. R. (1995). Measuring the prosocial personality. Advances in personality assessment, 10, 147-163.

Petty, R. E., \& Briñol, P. (2012). The elaboration likelihood model. In P. A. M. Van Lange, A. Kruglanski, \& E. T. Higgins (Eds.), Handbook of theories of social psychology (Vol. 1, pp. 224-245). London: SAGE.

Petty, R. E., \& Cacioppo, J. T. (1986). Communication and persuasion: Central and peripheral routes to attitude change. New York: Springer-Verlag.

Petty, R. E., \& Cacioppo, J. T. (1986). The elaboration likelihood model of persuasion. Advances in Experimental Social Psychology, 19, 123-205.

Petty, R. E., Wegener, D. T., \& Fabrigar, L. R. (1997). Attitudes and attitude change. Annual Review of Psychology, 48(1), 609-647.

Piliavin, J. A., Dovidio, J. F., Gaertner, S. L., \& Clark, R. D., III. (1981). Emergency intervention. New York: Academic. 
Polanin, J. R., Espelage, D. L., \& Pigott, T. D. (2012). A meta-analysis of school-based bullying prevention programs' effects on bystander intervention behavior. School Psychology Review, 41(1), 47-65.

Potter, S. J. (2012). Using a multimedia social marketing campaign to increase active bystanders on the college campus. Journal of American College Health, 60(4), 282-295.

Potter, S. J., Moynihan, M. M., \& Stapleton, J. G. (2011). Using social self-identification in social marketing materials aimed at reducing violence against women on campus. Journal of Interpersonal Violence, 26(5), 971-990.

Potter, S. J., \& Stapleton, J. G. (2012). Translating sexual assault prevention from a college campus to a United States military installation piloting the know-your-power bystander social marketing campaign. Journal of Interpersonal Violence, 27(8), 1593-1621.

Potter, S. J., Stapleton, J. G., \& Moynihan, M. M. (2008). Designing, implementing, and evaluating a media campaign illustrating the bystander role. Journal of Prevention \& Intervention in the Community, 36(1-2), 39-55.

Pöyhönen, V., Juvonen, J., \& Salmivalli, C. (2012). Standing up for the victim, siding with the bully or standing by? Bystander responses in bullying situations. Social Development, 21(4), 722-741.

Pöyhönen, V., \& Salmivalli, C. (2008). New directions in research and practice addressing bullying: Focus on defending behavior. Understanding and addressing bullying: An international perspective (pp. 26-43). In D. Pepler \& W. Craig (Eds.), Understanding and addressing bullying: An international perspective (PREVNet Series, Vol. 1, pp. 26-39). Bloomington, IN: Authorhouse.

Prentice, D. A., \& Miller, D. T. (1993). Pluralistic ignorance and alcohol use on campus: Some consequences of misperceiving the social norm. Journal of Personality and Social psychology, 64(2), 243-256.

Rothman, A. J., \& Salovey, P. (1997). Shaping perceptions to motivate healthy behavior: The role of message framing. Psychological Bulletin, 121(1), 3-9.

Rutkowski, G. K., Gruder, C. L., \& Romer, D. (1983). Group cohesiveness, social norms, and bystander intervention. Journal of Personality and Social Psychology, 44(3), 545-552.

Sandstrom, M., Makover, H., \& Bartini, M. (2013). Social context of bullying: Do misperceptions of group norms influence children's responses to witnessed episodes? Social Influence, 8(2-3), 196-215.

Sasson, C., Meischke, H., Abella, B. S., Berg, R. A., Bobrow, B. J., Chan, P. S., ... Masoudi, F. (2013). Increasing cardiopulmonary resuscitation provision in communities with low bystander cardiopulmonary resuscitation rates: A science advisory from the American 
Heart Association for healthcare providers, policymakers, public health departments, and community leaders. Circulation, 127, 1342-1350.

Shibata, K., Taniguchi, T., Yoshida, M., \& Yamamoto, K. (2000). Obstacles to bystander cardiopulmonary resuscitation in Japan. Resuscitation, 44(3), 187-193.

Shotland, R. L., \& Heinold, W. D. (1985). Bystander response to arterial bleeding: helping skills, the decision-making process, and differentiating the helping response. Journal of Personality and Social psychology, 49, 347-356.

Stewart, K., Pedersen, A., \& Paradies, Y. (2014). It's always good to help when possible, BUT ...: Obstacles to bystander anti-prejudice. The International Journal of Diversity in Education, 13(3), 39-53.

Turner, J. C. (1985). Social categorization and the self-concept: A social cognitive theory of group behavior. Advances in Group Processes: Theory and Research, 2, 77-122.

Valente, T. W., \& Pumpuang, P. (2007). Identifying opinion leaders to promote behavior change. Health Education \& Behavior, 34(6), 881-896.

Van den Bos, K., \& Lind, E. A. (2013). On sense-making reactions and public inhibition of benign social motives: An appraisal model of prosocial behavior. Advances in Experimental Social Psychology, 48, 1-58.

Weiner, B. (1993). On sin versus sickness: A theory of perceived responsibility and social motivation. American Psychologist, 48(9), 957-965.

Weiner, B. (1995). Judgments of responsibility: A foundation for a theory of social conduct. New York: Guilford Press.

Whatley, M. A. (2005). The effect of participant sex, victim dress, and traditional attitudes on causal judgments for marital rape victims. Journal of Family Violence, 20(3), 191-200.

Witte, K., \& Allen, M. (2000). A meta-analysis of fear appeals: Implications for effective public health campaigns. Health Education \& Behavior, 27(5), 591-615.

\section{Shawn Meghan Burn}

Department of Psychology and Child Development, California Polytechnic State University 